\title{
Impact of Structured Insulin Order Sets on Inpatient Hypoglycemia and Glycemic Control
}

\author{
Maria I. Kravchenko \\ Brooke Army Medical Center \\ Joshua M. Tate \\ Brooke Army Medical Center \\ Philip G. Clerc \\ Brooke Army Medical Center \\ Whitney L. Forbes \\ Wilford Hall Ambulatory Surgical Center \\ Morgan C. Gettle \\ Brooke Army Medical Center
}

See next page for additional authors

Tell us how you used this information in this short survey.

Follow this and additional works at: https://digitalcommons.unmc.edu/com_hosp_articles

\section{Recommended Citation}

Kravchenko, Maria I.; Tate, Joshua M.; Clerc, Philip G.; Forbes, Whitney L.; Gettle, Morgan C.; Wardian, Jana L. PhD; and Colburn, Jeffrey A., "Impact of Structured Insulin Order Sets on Inpatient Hypoglycemia and Glycemic Control" (2020). Journal Articles: Hospital Medicine. 26.

https://digitalcommons.unmc.edu/com_hosp_articles/26

This Article is brought to you for free and open access by the Hospital Medicine at DigitalCommons@UNMC. It has been accepted for inclusion in Journal Articles: Hospital Medicine by an authorized administrator of DigitalCommons@UNMC. For more information, please contact digitalcommons@unmc.edu. 


\section{Authors}

Maria I. Kravchenko, Joshua M. Tate, Philip G. Clerc, Whitney L. Forbes, Morgan C. Gettle, Jana L. Wardian $\mathrm{PhD}$, and Jeffrey A. Colburn 


\title{
IMPACT OF STRUCTURED INSULIN ORDER SETS ON INPATIENT HYPOGLYCEMIA AND GLYCEMIC CONTROL
}

\author{
Maria I. Kravchenko, MD ${ }^{1}$; Joshua M. Tate, MD ${ }^{1}$; Philip G. Clerc, MD ${ }^{1}$; Whitney L. Forbes, PhD';

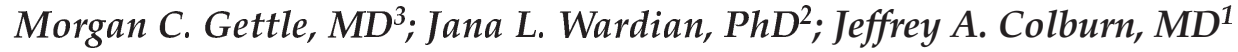

\begin{abstract}
Objective: In hospitalized patients, glycemic excursions outside recommended glycemic targets have been associated with increased morbidity and mortality. Despite recommendations to avoid use of correctional insulin alone for managing hyperglycemia, this approach remains common. We performed a quality improvement project aimed at both reducing hypoglycemic events and promoting increased use of basal insulin by updating our insulin order sets to reflect clinical practice guideline recommendations.
\end{abstract}

Methods: Brooke Army Medical Center correctional insulin order sets were modified to reflect higher treatment thresholds and targets, and a basal insulin order was added with a recommended weight-based starting dose. Pre- and postintervention analyses were performed. Patients were included if they were prescribed subcutaneous insulin during their hospital stay. The following outcomes were measured: (l) glucose levels, and (2) prescriptions for basal insulin.

Results: A significant reduction in hypoglycemia events was noted following the intervention (glucose $<70 \mathrm{mg} / \mathrm{dL}$ : $9.2 \%$ pre-intervention vs. $8.8 \%$ postinterven-

Submitted for publication July 19, 2019

Accepted for publication December 27, 2019

From the ${ }^{1}$ Department of Medicine, Endocrinology Service, Brooke Army Medical Center, Fort Sam Houston, Texas, ${ }^{2}$ Diabetes Center of Excellence, Wilford Hall Ambulatory Surgical Center, Lackland Air Force Base, Texas, and ${ }^{3}$ Department of Medicine, Brooke Army Medical Center, Fort Sam Houston, Texas.

Address correspondence to Dr. Maria Kravchenko, Brooke Army Medical Center, Department of Endocrinology, 3553 Roger Brooke Drive, Ft. Sam Houston, TX 78234.

E-mail: Maria.i.kravchenko.mil@mail.mil.

Published as a Rapid Electronic Article in Press at http: / / www.endocrine practice.org on January 22, 2020. DOI: 10.4158/EP-2019-0341

To purchase reprints of this article, please visit: www.aace.com/reprints. Copyright (C) 2020 AACE. tion; glucose $<55 \mathrm{mg} / \mathrm{dL}: 4.2 \%$ pre-intervention vs. $2.2 \%$ postintervention). When excluding patients that were ordered correctional insulin alone but did not receive a dose, an increase in basal insulin use was seen (50\% preintervention vs. $61 \%$ postintervention). Rates and severity of hyperglycemia (glucose $>180 \mathrm{mg} / \mathrm{dL}$ ) remained unchanged.

Conclusion: The alteration in insulin order set parameters resulted in a significant reduction in hypoglycemia without significant increases in hyperglycemia. Although basal insulin use increased, optimal dosing recommendations were not often utilized. Further interventions are necessary to reduce hyperglycemia. (Endocr Pract. 2020;26:523-528)

\begin{abstract}
Abbreviations:
CPOE = computerized provider order entry; EMR = electronic medical record; HbA1c = hemoglobin A1c; $\mathbf{L O S}=$ length of stay; $\mathbf{Q I}=$ quality improvement; $\mathbf{S S I}=$ sliding scale insulin
\end{abstract}

\section{INTRODUCTION}

Diabetes mellitus is one of the most common diseases encountered by health care professionals, affecting over $9 \%$ of the population of the United States (1), with manifestations that involve almost every organ in the body. Patients with diabetes are more likely to require hospital admission (2-4) and have more complications and a longer length of stay (LOS) (5-7). Additionally, patients without a prior diagnosis of diabetes may exhibit hyperglycemia during hospitalization (8). Hyperglycemia is strongly associated with adverse outcomes in hospitalized patients, including adverse surgical outcomes, increased LOS, and higher mortality (8-11). While there is a paucity of evidence for reduction in hospital-related mortality, medical therapy

This material is protected by US copyright law. To purchase commercial reprints of this article, visit www.aace.com/reprints. For permission to reuse material, please access www.copyright.com or contact the Copyright Clearance Center, Inc. (CCC). 
to reduce hyperglycemia has been shown to reduce perioperative infection rates and improve wound healing (12-14). Any treatment of hyperglycemia must be balanced against the risk of treatment-induced hypoglycemia, which also substantially increases morbidity and mortality and can be more acutely life threatening (15-17). To achieve this equilibrium, the American Diabetes Association, the American Association of Clinical Endocrinologists, and the Endocrine Society have recommended glycemic targets of 100 to $180 \mathrm{mg} / \mathrm{dL}$ for most hospitalized patients with diabetes mellitus (18-20).

Insulin has been the mainstay of treatment for inpatient hyperglycemia. Particularly, "basal bolus" regimens are recommended by clinical practice guidelines (18-20). Regimens incorporating basal insulin have been shown to be safe and effective $(21,22)$. Despite this wealth of evidence, use of correction dose alone or "sliding scale" insulin (SSI) regimens remains prevalent $(23,24)$. This is primarily due to clinical inertia as well as fear of inducing hypoglycemia with long-acting insulin (25). However, SSI regimens are less effective at achieving glycemic targets and demonstrate no difference in hypoglycemia rates $(21,26)$.

Structured insulin order sets, particularly with computerized provider order entry (CPOE) in an electronic medical record (EMR), have demonstrated efficacy in improving insulin use patterns and glycemic control when compared to verbal or freestyle handwritten orders (26). In the era of widespread EMR use, insulin order sets with CPOE have become the standard of care in inpatient settings. Evidence is lacking, however, regarding their effect on glycemic management and prescribing patterns in a "realworld" setting.

\section{METHODS}

A quality improvement (QI) project was performed by a multidisciplinary team at Brooke Army Medical Center (BAMC), a 425-bed academic military hospital, to improve insulin ordering practices and glycemic management for adult inpatients with hyperglycemia. The hospital serves active duty military personnel, their families, military retirees, and civilian trauma patients. An EMR is used for all inpatient orders and structured insulin order sets have been in place for many years. However, there is no formal process in place to ensure insulin order sets reflect changing clinical practice guidelines. In addition, the EMR does not have the capability to construct built-in treatment algorithms.

To address inpatient diabetes management within our complex healthcare system, we implemented a supportive mechanism for QI, the Plan-Do-Study-Act (PDSA) method (27). PDSA Cycle 1 implemented two separate targets for intervention: reduction of inpatient hypoglycemia and increasing the prescription of basal insulin as opposed to
SSI regimens alone. During the planning phase, a retrospective review of inpatient glycemic management within our institution was performed. Six months of data were collected on adult ( $\geq 18$ years of age) inpatients admitted to BAMC medical, surgical, and critical care units for $\geq 24$ hours, who received subcutaneous insulin during their hospital stay. Women admitted to the obstetrics unit were excluded. The collected data included serum glucose, fingerstick blood glucose, time and dose of administered insulin, hemoglobin A1c (HbA1c), and the admitting service. Only patients with a length of stay $>24$ hours were included, as it was felt that a shorter monitoring time would not accurately represent the impact of any interventions. A mean glucose value was recorded for each patient with at least 3 recorded glucose values. To reduce the risk of sampling error, a subanalysis was performed for patients with at least 6 recorded glucose values. An uncontrolled patient stay was defined as a mean glucose value $>180 \mathrm{mg} /$ $\mathrm{dL}$, as this is above the glycemic target for clinical practice guidelines (18-20). Hypoglycemia was defined as pointof-care (POC) or serum glucose $<70 \mathrm{mg} / \mathrm{dL}$ and severe hypoglycemia as POC or serum glucose $<55 \mathrm{mg} / \mathrm{dL}$ (28). We calculated the percentage of monitored patients who experienced at least one episode of hypoglycemia or severe hypoglycemia over the course of their admission. Insulin regimens were characterized as basal bolus plus correction, basal plus correction, or correction only. The percentage of insulin regimens incorporating basal insulin was calculated for each sampled month. The results of the planning phase (Table 1) showed that the majority of inpatients with hyperglycemia did not meet the glycemic target of 80 to $180 \mathrm{mg} / \mathrm{dL}$. Of additional concern, a higher than expected rate of hypoglycemia was identified.

During the planning phase review, the primary factors identified as contributors to poor management of hyperglycemia were ( 1 ) overreliance on correction-only insulin regimens or (2) suboptimal basal insulin dose for basal plus correction insulin regimens. Possible additional factors identified by house staff and nursing staff included lack of attention to glucose by providers and lack of knowledge about guideline recommended management. The main factor identified as contributing to hypoglycemia was a very aggressive correctional insulin scale. All insulin correction scales were built to target a glucose value of 100 $\mathrm{mg} / \mathrm{dL}$, and no guidance was provided in the order sets to aid the selection of an appropriate correction scale. As a result, patients were receiving correction doses that were higher than physiologically required, such as patients with very mild stress hyperglycemia receiving doses of insulin which subsequently caused hypoglycemia.

\section{Interventions}

To improve glycemic control, the insulin order sets for adult medical, surgical, and critical care units were updated. To address hypoglycemia specifically, the correc- 


\begin{tabular}{|c|c|c|c|c|}
\hline \multicolumn{5}{|c|}{$\begin{array}{c}\text { Table } 1 \\
\text { Glycemic Control - Pre-intervention }\end{array}$} \\
\hline & $\begin{array}{l}\text { Average glucose } \\
(\mathrm{mg} / \mathrm{dL})\end{array}$ & $\begin{array}{l}\text { Percent of patients } \\
\text { with any BG out of } \\
\text { target range }\end{array}$ & $\begin{array}{c}\text { Percent of } \\
\text { patients with BG } \\
<70 \mathrm{mg} / \mathrm{dL}\end{array}$ & $\begin{array}{c}\text { Percent of } \\
\text { patients with BG } \\
<55 \mathrm{mg} / \mathrm{dL}\end{array}$ \\
\hline SSI only & 176 & 63 & 7 & 2 \\
\hline Basal + SSI & 190 & 83 & 16 & 5 \\
\hline Basal/Bolus + SSI & 191 & 90 & 23 & 9 \\
\hline
\end{tabular}

tion insulin protocols were rewritten so that no correction insulin was administered until blood glucose was $>180$ $\mathrm{mg} / \mathrm{dL}$ (20). To simplify implementation and increase utilization, one glucose target $(150 \mathrm{mg} / \mathrm{dL})$ was provided for all correction insulin and chosen based on clinical practice guideline targets of 100 to $180 \mathrm{mg} / \mathrm{dL}$ (18-20). Additionally, comments were added to the EMR order sets which provided guidance regarding the appropriate selection of a correction insulin scale based on the following patient clinical characteristics: age, weight, renal function, and use of glucocorticoids. Since it was expected that these changes would result in increased rates of hyperglycemia, nursing call parameters were added with instructions to contact a provider if three consecutive blood glucose values were $>180 \mathrm{mg} / \mathrm{dL}$ so that insulin orders could be updated in an expedited fashion.

To address hyperglycemia specifically, an easily accessible order for insulin glargine was added to all insulin order sets, with a recommended starting dose of 0.2 units/kg body weight. In-person informational briefs were given to medical and surgical residents during their educational conferences, publicizing the changes to the insulin order sets, with recommendations to use basal insulin in all patients with hyperglycemia. An insulin ordering guide was also added to the locally published house staff manual. The former insulin order sets were deleted from the EMR to avoid confusion.

\section{Measures and Analyses}

During the 3-month follow-up period, data were collected to assess insulin use patterns, glycemic management, and hypoglycemic episodes. The same criteria were used for inclusion as for the pre-intervention analysis.

\section{Statistical Analysis}

All outcomes were analyzed comparing baseline to postintervention. Categorical data were summarized using counts and percentages and analyzed using a chisquared test. All continuous variables were summarized using means and standard deviations and analyzed using the Kruskal-Wallis test. Significance was established for $P$ values $<.05$.

\section{RESULTS}

A total of 1,423 patient hospital-stays were included in the analysis: 697 pre-intervention and 726 postintervention. Average patient age, weight, and LOS were similar in both groups.

\section{Hypoglycemia}

Table 2 summarizes the results for hypoglycemia and severe hypoglycemia in the study population. The intervention resulted in significantly less severe hypoglycemia compared to baseline.

\section{Glycemic Control}

Overall, no significant change was seen in overall mean glucose or number of patients with hyperglycemia (defined as any glucose $>180 \mathrm{mg} / \mathrm{dL}$ ) after the intervention. However, a significant increase was seen in uncontrolled patient stays, defined by mean glucose $>180 \mathrm{mg} / \mathrm{dL}$. Table 3 summarizes the results for glycemic control. A subanalysis was performed for patients that had $\geq 6$ recorded glucose values to reduce the risk of sampling error; the results were not significantly different. Of note, the mean HbA1c was significantly higher in the postintervention group when compared to pre-intervention $(8.0 \%$ [64 $\mathrm{mmol} / \mathrm{mol}] \mathrm{vs}$. $7.1 \%$ [54 $\mathrm{mmol} / \mathrm{mol}]$, respectively).

\section{Insulin Use Patterns}

Table 4.1 demonstrates the shift in insulin prescribing patterns in the 3 months prior to intervention compared to postintervention, correlated with average HbA1c. A portion of patients on SSI only (22\% pre-intervention vs. $38 \%$ postintervention) were noted to maintain their blood glucose within range without actually receiving any insulin. Table 4.2 shows insulin prescribing patterns when these patients were excluded from the analysis. Both analyses showed a significant increase in orders for basal insulin.

\section{DISCUSSION}

Our QI project demonstrated several important lessons which may be of use for other institutions aiming to 
improve inpatient glycemic management. The most valuable outcome of our project was to identify some pitfalls of standardized insulin order sets and to demonstrate a $50 \%$ reduction in episodes of severe hypoglycemia by adjusting insulin order sets to fit recommendations with clinical practice guidelines. Additionally, we demonstrated that increased use of basal insulin did not result in higher hypoglycemia rates, addressing one of the main barriers to use of basal insulin in the hospital.
Despite the familiarity of the endocrinology department with current inpatient glycemic targets based on clinical practice guidelines, the insulin order sets, which had been developed by endocrinology staff, did not reflect best evidence-based practices and likely led to the high baseline rates of hypoglycemia in our institution. The previous order set had been in place for several years, predating the less stringent glycemic targets that are currently recommended by clinical practice guidelines. This demon-

\begin{tabular}{|c|c|c|c|}
\hline \multicolumn{4}{|c|}{$\begin{array}{c}\text { Table } 2 \\
\text { Hypoglycemia Rates }\end{array}$} \\
\hline & Baseline & Postintervention & $P$ value \\
\hline Monitored patient-stays & 697 & 726 & \\
\hline Stays with hypoglycemia ${ }^{\mathrm{a}}, \mathrm{n}(\%)$ & $64(9.18)$ & $64(8.82)$ & .73 \\
\hline Stays with severe hypoglycemia, n (\%) & $29(4.16)$ & $16(2.20)$ & .008 \\
\hline
\end{tabular}

\begin{tabular}{|c|c|c|c|}
\hline \multicolumn{4}{|c|}{$\begin{array}{c}\text { Table } 3 \\
\text { Hyperglycemia Rates }\end{array}$} \\
\hline & Baseline & Postintervention & $P$ value \\
\hline Monitored patient-stays & 697 & 726 & \\
\hline Mean glucose $\pm \mathrm{SD}(\mathrm{mg} / \mathrm{dL})$ & $176 \pm 46$ & $180 \pm 53$ & \\
\hline Stays with any hyperglycemia, n (\%) & $575(82.50)$ & $584(80.44)$ & .145 \\
\hline Uncontrolled patient stays, n (\%) & $278(39.89)$ & $323(44.49)$ & $<.011$ \\
\hline
\end{tabular}

\begin{tabular}{|l|c|c|c|}
\hline \multicolumn{4}{|c|}{$\begin{array}{c}\text { Table 4.1 } \\
\text { Insulin Prescribing Patterns }\end{array}$} \\
\hline & Baseline & Postintervention & Average HbA1c \\
\hline Monitored patient-stays & 697 & 726 & \\
\hline SSI only (\%) ${ }^{\text {a }}$ & $388(56)$ & $352(48)$ & $6.4 \%(46 \mathrm{mmol} / \mathrm{mol})$ \\
\hline Basal \pm SSI $(\%)$ & $197(28)$ & $209(29)$ & $8.4 \%(68 \mathrm{mmol} / \mathrm{mol})$ \\
\hline Basal/Bolus \pm SSI $(\%)$ & $111(16)$ & $162(22)$ & $8.8 \%(73 \mathrm{mmol} / \mathrm{mol})$ \\
\hline Bolus \pm SSI $(\%)$ & $1(<1)$ & $3(<1)$ & \\
\hline $\begin{array}{l}\text { Abbreviations: HbA1c }=\text { hemoglobin A1c; SSI = sliding scale insulin. } \\
\text { a } P \text { value .008 for change in SSI only prescriptions. }\end{array}$ \\
\hline
\end{tabular}

\begin{tabular}{|c|c|c|c|}
\hline \multicolumn{4}{|c|}{$\begin{array}{c}\text { Table } 4.2 \\
\text { Insulin Prescribing Pattern Excluding Patients Who } \\
\text { Maintained Blood Glucose Within Range Without Receiving Insulin }\end{array}$} \\
\hline & Baseline & Postintervention & Average HbA1c \\
\hline Monitored patient-stays & 612 & 594 & \\
\hline SSI only $(\%)^{\mathrm{a}}$ & $303(50)$ & $220(37)$ & $6.7 \%(50 \mathrm{mmol} / \mathrm{mol})$ \\
\hline Basal \pm SSI $(\%)$ & $197(32)$ & $209(35)$ & $8.4 \%(68 \mathrm{mmol} / \mathrm{mol})$ \\
\hline Basal/Bolus \pm SSI $(\%)$ & $111(18)$ & $162(26)$ & $8.8 \%(73 \mathrm{mmol} / \mathrm{mol})$ \\
\hline Bolus \pm SSI (\%) & $1(<1)$ & $3(<1)$ & \\
\hline \multicolumn{4}{|c|}{$\begin{array}{l}\text { Abbreviations: } \mathrm{HbA} 1 \mathrm{c}=\text { hemoglobin A1c; } \mathrm{SSI}=\text { sliding scale insulin. } \\
{ }^{a} P \text { value } .005 \text { for change in SSI only prescriptions. }\end{array}$} \\
\hline
\end{tabular}


strates the need to regularly re-evaluate existing structured order sets. Our QI project revealed a disconnect between clinical practice guidelines (which recommend a glucose threshold for insulin utilization and a premeal and random glucose target range) and CPOE functionality of correction insulin order sets (which ideally provide a more specific glucose target as a basis for correction insulin doses). We have demonstrated that a correction insulin glucose target of $150 \mathrm{mg} / \mathrm{dL}$ may be more favorable than $100 \mathrm{mg} / \mathrm{dL}$ for minimizing hypoglycemia in the inpatient setting, and any resultant increase in hyperglycemia would be better managed by increasing utilization of basal insulin. It is likely that the improvement in hypoglycemia rates was directly related to the changes in insulin order sets, but we recognize that the design of our intervention does not confer the causality that could be attributed in a randomized controlled trial. We did not account for patient variables which may have confounded the rate of hypoglycemia, such as time spent nil per os, personal history of gastric bypass, or development of acute kidney injury. However, it is of interest that the rate of adherence to the new order set by house staff approached $100 \%$, with the sole exception being patients admitted to the bariatric surgery service, for whom a custom insulin protocol is utilized. Exclusion of bariatric surgery patients did not affect the final results. The educational efforts conducted at the same time would not be expected to reduce hypoglycemia rates, since the education was primarily focused on increasing the use of basal insulin.

The intervention did significantly improve basal insulin prescribing patterns, with an additional $12 \%$ of patients with hyperglycemia receiving basal insulin after the intervention. In contrast to previous studies investigating the use of structured insulin order sets $(21,26)$, our intervention did not result in any improvement in glycemic control; in fact, the number of patient-stays with a mean glucose $>180 \mathrm{mg} / \mathrm{dL}$ actually increased. The majority of patients did not meet glycemic targets. There are several possible explanations for this finding. First, although the majority of patients were receiving basal insulin after the intervention, $65 \%$ of patients were not receiving at least the minimum recommended dose of 0.2 units $/ \mathrm{kg}$. This suggests that many providers remain uncomfortable with prescribing even the minimum recommended basal insulin dose in the inpatient setting. Second, a lack of titration was seen, with many patients receiving the same dose of insulin throughout their stay despite glucose values remaining above target range. Third, we did not control for variables that may have confounded hyperglycemia, such as steroid use, prescribed diet, infections, and postoperative status. Finally, we did note that the average $\mathrm{HbA} 1 \mathrm{c}$ was significantly higher in the postintervention group, indicating that the patients admitted during this time period had worse glycemic control at baseline. This could potentially confound the results by masking any improvement in hyperglycemia due to insu- lin prescribing changes. However, we would expect this effect to be most prominent during the first 24 hours of admission, and all included patients had a LOS $>24$ hours. Moreover, the subanalysis of patients with at least 6 blood glucose readings showed identical results.

A significant proportion of patients who were ordered correctional insulin never received any insulin due to absence of significant hyperglycemia. This increases the burden on nursing staff due to the frequency of glucose checks and the documentation requirements. Consideration of decreased frequency of glucose monitoring in patients without hypoglycemia or hyperglycemia after 24 hours may be a potential target for a future process improvement project.

Ultimately, structured insulin order sets aligned with clinical practice guidelines, even with prescribing prompts, were not sufficient to achieve recommended glycemic targets. Previous studies have demonstrated additional value in utilizing an EMR-based treatment algorithm (26), but our EMR is not able to support this capability. However, in institutions whose prescribing systems allow integration of algorithms, this is likely to be more effective in managing hyperglycemia. For other institutions that do not support this capability, we suggest that a review of insulin order sets may be useful.

\section{CONCLUSION}

Minor alterations in insulin order set parameters resulted in a significant reduction in hypoglycemia without a significant increase in hyperglycemia. Further interventions are necessary to reduce hyperglycemia. Periodic review of existing insulin order sets is a simple method to improve inpatient glycemic control.

\section{DISCLOSURE}

The authors have no multiplicity of interest to disclose. The view(s) expressed herein are those of the author(s) and do not reflect the official policy or position of Brooke Army Medical Center, the U.S. Army Medical Department, the U.S. Army Office of the Surgeon General, the Department of the Army, the Department of the Air Force, or the Department of Defense or the U.S. Government.

\section{REFERENCES}

1. Centers for Disease Control and Prevention. National Diabetes Statistics Report, 2017. Available at: www.cdc.gov/diabetes/pdfs/ data/statistics/national-diabetes-statistics-report.pdf. Accessed June 21, 2019.

2. Jiang HJ, Stryer D, Friedman B, Andrews R. Multiple hospitalizations for patients with diabetes. Diabetes Care. 2003;26: 1421-1426.

3. Chanchlani N, Russell E. Causes and patterns of readmissions in patients with common comorbidities: retrospective cohort study. BMJ. 2014;348:g1667. 
4. McCoy RG, Lipska KJ, Herrin J, Jeffery MM, Krumholz HM, Shah ND. Hospital readmissions among commercially insured and Medicare Advantage beneficiaries with diabetes and the impact of severe hypoglycemic and hyperglycemic events. J Gen Intern Med. 2017:32:1097-1105

5. Comino EJ, Harris MF, Islam MF, et al. Impact of diabetes on hospital admission and length of stay among a general population aged 45 year or more: a record linkage study. BMC Health Serv Res. 2015;15:12.

6. Malone M, Lau NS, White J, et al. The effect of diabetes mellitus on costs and length of stay in patients with peripheral arterial disease undergoing vascular surgery. Eur J Vasc Endovasc Surg. 2014;48:447-451

7. Menzin J, Korn JR, Cohen J, et al. Relationship between glycemic control and diabetes-related hospital costs in patients with type 1 or type 2 diabetes mellitus. J Manag Care Pharm. 2010;16: 264-275.

8. Umpierrez GE, Isaacs SD, Bazargan N, You $\mathbf{X}$, Thaler LM, Kitabchi AE. Hyperglycemia: an independent marker of in-hospital mortality in patients with undiagnosed diabetes. J Clin Endocrinol Metab. 2002:87:978-982.

9. McAlister FA, Majumdar SR, Blitz S, Rowe BH, Romney J, Marrie TJ. The relation between hyperglycemia and outcomes in 2,471 patients admitted to the hospital with community-acquired pneumonia. Diabetes Care. 2005;28:810-815.

10. Hirata Y, Tomioka H, Sekiya R, et al. Association of hyperglycemia on admission and during hospitalization with mortality in diabetic patients admitted for pneumonia. Intern Med. 2013;52:2431-2438.

11. Monteiro S, Monteiro P, Gonçalves F, Freitas M,A. Providência L. Hyperglycaemia at admission in acute coronary syndrome patients: prognostic value in diabetics and non-diabetics. Eur $J$ Cardiovasc Prev Rehabil. 2010;17:155-159.

12. Kwon S, Thompson RE, Dellinger P, Rogers T, Flum D. Importance of perioperative glycemic control in general surgery: a report from the surgical care and outcomes assessment program. J Surg Res. 2012;172:274.

13. Navaratnarajah M, Rea R, Evans R, et al. Effect of glycaemic control on complications following cardiac surgery: literature review. J Cardiothorac Surg. 2018;13:10.

14. Murad MH, Coburn JA, Coto-Yglesias F, et al. Glycemic control in non-critically ill hospitalized patients: a systematic review and meta-analysis. J Clin Endocrinol Metab. 2012;97: 49-58.

15. NICE-Sugar Study Investigators, Finfer S, Liu B, et al. Hypoglycemia and risk of death in critically ill patients. $N$ Engl $J$ Med. 2012;367:1108-1118.
16. Kagansky N, Levy $\mathbf{S}$, Rimon E, et al. Hypoglycemia as a predictor of mortality in hospitalized elderly patients. Arch Intern Med. 2003;163:1825-1829.

17. Garg R, Hurwitz S, Turchin A, Trivedi A. Hypoglycemia, with or without insulin therapy, is associated with increased mortality among hospitalized patients. Diabetes Care. 2013;36:1107-1110.

18. Umpierrez GE, Hellman R, Korytkowski MT, et al. Management of hyperglycemia in hospitalized patients in non-critical care setting: an Endocrine Society clinical practice guideline. J Clin Endocrinol Metab. 2012;97:16-38.

19. Moghissi ES, Korytkowski MT, DiNardo M, et al. American Association of Clinical Endocrinologists and American Diabetes Association consensus statement on inpatient glycemic control. Diabetes Care. 2009;32:1119-1131.

20. American Diabetes Association. Diabetes care in the hospital: standards of medical care in diabetes 2019. Diabetes Care. 2019;42(suppl 1):S173-S181.

21. Umpierrez GE, Smiley D, Zisman A, et al. Randomized study of basal-bolus insulin therapy in the inpatient management of patients with type 2 diabetes (RABBIT 2 trial). Diabetes Care. 2007;30:2181-2186.

22. Ena J, Gómez-Huelgas $\mathbf{R}$, Romero-Sánchez $\mathbf{M}$, et al. Hyperglycemia management in patients admitted to internal medicine in Spain: a point-prevalence survey examining adequacy of glycemic control and guideline adherence. Eur J Intern Med. 2015;26:392-398.

23. Umpierrez GE, Palacio A, Smiley D. Sliding scale insulin use: myth or insanity? Am J Med. 2007;120:563-567.

24. Ambrus DB, O'Connor MJ. Things we do for no reason: slidingscale insulin as monotherapy for glycemic control in hospitalized patients. J Hosp Med. 2019;14:114-116.

25. Queale WS, Seidler AJ, Brancati FL. Glycemic control and sliding scale insulin use in medical inpatients with diabetes mellitus. Arch Intern Med. 1997; 157:545-552.

26. Maynard G, Lee J, Phillips G, Fink E, Renvall M. Improved inpatient use of basal insulin, reduced hypoglycemia, and improved glycemic control: effect of structured subcutaneous insulin orders and an insulin management algorithm. $J$ Hosp Med. 2009;4:3-15.

27. Taylor MJ, McNicholas C, Nicolay C, Darzi A, Bell D, Reed JE. Systematic review of the application of the plan-do-studyact method to improve quality in healthcare. BMJ Qual Saf. 2014;23:290-298.

28. International Hypoglycaemia Study Group. Glucose concentrations of less than $3.0 \mathrm{mmol} / \mathrm{L}(54 \mathrm{mg} / \mathrm{dL})$ should be reported in clinical trials: a joint position statement of the American Diabetes Association and the European Association for the Study of Diabetes. Diabetes Care. 2017;40:155-157. 
Reproduced with permission of copyright owner. Further reproduction prohibited without permission. 